\title{
Interactive Effect between Economic Development and Ecological Environment Quality in Changsha-Zhuzhou-Xiangtan Based on EKC Hypothesis
}

\author{
Yudong Guo \\ School of Economics and Management \\ China University of Geosciences \\ WuHan, China \\ Hunan University of Technology \\ Zhuzhou, China \\ Kirsty1012@163.com
}

\author{
Jie Yang \\ School of Business \\ Hunan University of Technology \\ Zhuzhou, China
}

\begin{abstract}
Based on the Environmental Kuznets Curve(EKC)hypothesis, this paper use the method of principal component analysis(PCA)to extract ChangshaZhuzhou-Xiangtan's ecological environmental pollution factors. Regression models was taken to verify the interactive effect between Changsha-Zhuzhou-Xiangtan's economic development and ecological environment degradation which by using Changsha-ZhuzhouXiangtan's gross domestic product(GDP)per capita and sulfur dioxide, nitrogen oxides ,total suspended particulate emission data from 1990 to 2010 . The result shows that the fitting curve between environmental pollution factors and GDP per capita is conform to environmental Kuznets curve. Changsha-ZhuzhouXiangtan enters to EKC's later stage which ecological environment degradation begins to falls with GDP per capita increasing.
\end{abstract}

Keywords- Economic Development; Ecological Environment Degradation; Environmental Kuznets Curve; Principal Component Analysis; Changsha-Zhuzhou-Xiangtan

\section{INTRODUCTION}

Economic development lead to ecological environment destroy and resource consumption inevitably in the process of industrialization, at the same time, excessive pollution of ecological environment is bound to restrain economic development. How the effects economic development processes dictate ecological environmental changes. Many researcher find principles between economic development and ecologic environment through the study of EKC hypothesis.

EKC hypothesis presents a close relationship between economic development (per capita income) and environment quality. This curve indicates that a nation in a low economic development level, its environmental pollution is lighter. When nation's per capita income close to a critical point, economic development initially degrades environmental quality, but with economic further increase to a turning point, the relationship appears to reverse and the trend of environmental degradation starts to reduce. This relationship produces an inverted $\mathrm{U}$-shape curve, where ecological environment degradation first rises and then falls with nation's economic increasing.

EKC hypothesis became prevail after 1990s for its potentiality and promise of finding a final solution between ecological environment degradation and economic development. Many researchers engage in various test on EKC hypothesis.Some researchers such as Grossman and Krueger(1991) [1], Panayotou (1993)[2], Selden and Song(1994) [3], Danesh Miah (2010)[6],Mohamed (2010)[7] , Muhammad (2012)[8], George(2013)[9], Li(2010)[10] demonstrated an inverted U-shaped curve between economic development and environmental degradation for prove EKC hypothesis' existence with peaks at the early stage of development followed by declines at the later stage. However, not all researches support the EKC hypothesis' existence. Diao (2009) developed an N-sharped curve on six pollution indices in Jiaxing[4]. Elif and Serap found the relationship between $\mathrm{SO}, \mathrm{CO} 2, \mathrm{PM} 10$ emissions and income in Turkey is not an environmental kuznets curve [5].

In terms of above researches, this paper tries to investigate the relationship between some ecological environmental pollution factors and GDP per capita for Changsha-Zhuzhou-Xiangtan region.Changsha-ZhuzhouXiangtan is the core region of Hunan province in the economic development, three cities are first, second, Fifth in Hunan (according to the Hunan statistical yearbook 2011 version). Three cities' land area account for $13.3 \%$ of Hunan province, Three cities' population account for $19.6 \%$ of Hunan province. In 2011, Changsha-ZhuzhouXiangtan's GDP is 827 billion yuan.

In recent years, Changsha-Zhuzhou-Xiangtan adhere to accelerate the development strategy, promote the agriculture modernization constantly, reduce the proportion of agriculture, strengthen new industry-oriented growth pattern, optimize and upgrade industrial structure continuously, the three industry output value was changed from 37.5:33.6:28.9 in 1990 to $14.7: 46: 39.2$ in 2010 , industrial development has become a new bright spot of economic growth. Changsha-Zhuzhou-Xiangtan realized the industrialization from the initial stage to the middle stage successfully.

Changsha-Zhuzhou-Xiangtan has carried out the 
industry structure adjustment policy that give priority to the light industry development from 1990 to 1998, the traditional industry such as textile and clothing become the main body. In recent years, Changsha-Zhuzhou-Xiangtan enhance the industrialization rapidlly, the proportion of light and heavy industry continue to decline and the proportion of heavy industry continue to rise. Figure 1 shows that the industrial structure's changes in the Changsha-ZhuzhouXiangtan.

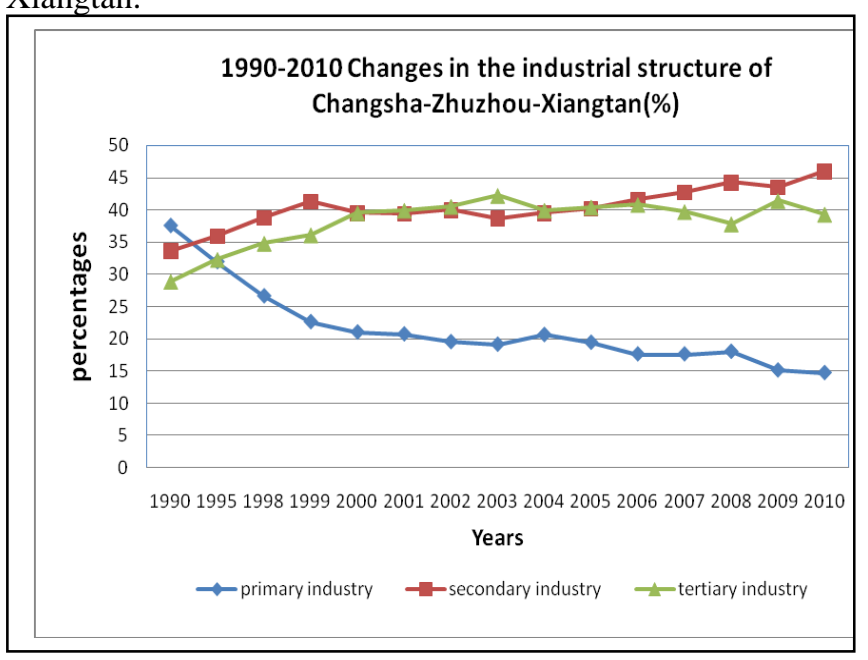

Figure 1. 1990-2010 changes in the industrial structure of ChangshaZhuzhou-Xiangtan data sources : statistical information of HUNAN (http://www.hntj.gov.cn/tjgb/szgb/)

\section{CONSTRUCTION OF EVALUATING INDICATOR}

\section{A. Data Sources}

Considering data availability, this paper selected Changsha-Zhuzhou-Xiangtan's economic and environmental data from 1990 to 2010. Among these data, the GDP per capita (yuan / person) mainly comes from the "statistical yearbook of Hunan province", Hunan Province Statistical Information Network (http://www.hntj.gov.cn/); sulfur dioxide emission (ten thousand tons), nitrogen oxide emissions (ten thousand tons), total suspended particulate emissions (ten thousand tons), carbon monoxide emissions (ten thousand tons), photochemical oxidant emissions (ten thousand tons), total oxidant emissions (ten thousand tons), mainly comes from the "1990-2010 Hunan environmental state Bulletin ".

\section{B. Principal Component Analysis of Environmental Quality Indicator}

To find the relationship between the ChangshaZhuzhou-Xiangtan environmental quality and economic development, integrate the above 6 environmental quality indicators and extract false variables, by calculate the comprehensive factor score to measure the quality of the environment, this process called FACTOR SPSS19.0, the results is following:
TABLE I. KMO AND BARTLETT'S TEST

\begin{tabular}{|l|l|c|}
\hline \multicolumn{3}{|c|}{ KMO and Bartlett's Test } \\
\hline Kaiser-Meyer-Olkin Measure of Sampling & 0.701 \\
\hline \multirow{3}{*}{$\begin{array}{l}\text { Bartlett's Test of } \\
\text { Sphericity }\end{array}$} & Approx. Chi-Square & 102.674 \\
\cline { 2 - 3 } & $\mathrm{df}$ & 15 \\
\cline { 2 - 3 } & Sig. & 0.000 \\
\hline
\end{tabular}

Table1 shows that KMO's value was 0.701 greater than 0.5 , the value within an acceptable range, and the significant probability was 0 far less than 0.05 . Therefore, there is significant relationship between several factors; the situation is suitable for factor analysis.

TABLE II. CHARACTERISTIC VALUE AND THE CONTRIBUTION RATE

\begin{tabular}{|c|c|c|c|}
\hline $\begin{array}{c}\text { principal } \\
\text { component }\end{array}$ & $\begin{array}{c}\text { characteristic } \\
\text { value }\end{array}$ & $\begin{array}{c}\text { variance } \\
\text { contribution rate }\end{array}$ & $\begin{array}{c}\text { cumulative variance } \\
\text { contribution rate }\end{array}$ \\
\hline 1 & 3.607 & 53.39 & 53.39 \\
\hline 2 & 1.727 & 25.562 & 78.952 \\
\hline 3 & 1.115 & 16.504 & 95.456 \\
\hline 4 & 0.187 & 2.768 & 98.224 \\
\hline 5 & 0.088 & 1.303 & 99.526 \\
\hline 6 & 0.032 & 0.474 & 100 \\
\hline
\end{tabular}

Table2 shows that the first 3 factors' cumulative variance contribution rate is $95.456 \%$ higher than $85 \%$ after extraction and rotation, their characteristic value are greater than 1 ,therefore 3 common factors can be extracted.

TABLE III. PRINCIPAL COMPONENT FACTOR LOADING MATRIX

\begin{tabular}{|c|c|c|c|}
\hline \multirow{2}{*}{ sulfur dioxide emission } & \multicolumn{3}{|c|}{ principal component } \\
\cline { 2 - 4 } & 1 & 2 & 3 \\
\hline nitrogen oxide emissions & 0.134 & 0.598 & -0.087 \\
\hline total suspended particulate emissions & -0.212 & 0.042 & 0.654 \\
\hline carbon monoxide emissions & 0.383 & -0.034 & -0.12 \\
\hline photochemical oxidant emissions & -0.689 & 0.547 & 0.076 \\
\hline total oxidant emissions & -0.146 & -0.067 & 0.032 \\
\hline
\end{tabular}

Table3 is principal component factor loading matrix, according to the factor model can calculate each indicator's scores in the 3 principal factors, and use every factor's contribution rate as its weight to acquire principal component comprehensive equation (1):

$$
F=0.53390 F_{1}+0.25562 F_{2}+0.16504 F_{3}
$$

\section{ANALYSIS OF RELATIONSHIP BETWEEN CHANGSHA- ZHUZHOU-XIANGTAN'S ECONOMIC DEVELOPMENT AND ECOLOGICAL ENVIRONMENTAL QUALITY}

\section{A. Construciton of Regression Model}

This paper uses the three polynomial model to regressive analyses the interactive effect between economic development and ecological environment quality in ChangZhu-Tan. The form model is shown in equation (2): 


$$
Y_{t}=\beta_{0}+\beta_{1} x_{t}+\beta_{2} x_{t}^{2}+\beta_{3} x_{t}^{3}+\varepsilon_{t}
$$

where $Y$ is a pollution index with a low value meaning a high ecological environmental quality; $x$ is the GDP per capita that indicating the level of economic development; $t$ is the time index; $\beta_{0}$ is the constant; $\beta_{1}, \beta_{2}$ and $\beta_{3}$ are the coefficients of explanatory variables; and $\varepsilon$ is the normally distributed error term.

Using equation (2), we can test the various forms of relationship between ecological environmental quality and economic development as follows:

- $\beta_{1}=\beta_{2}=\beta_{3}=0$. A flat pattern or no relationship between economic development and ecological environmental quality, the graphic is a horizontal line.

- $\beta_{1} \neq 0, \beta_{2}=\beta_{3}=0$. A linear relationship between economic development and ecological environmental quality.,the graphic is a inclined line.

- $\quad \beta_{1}>0, \beta_{2}<0, \quad \beta_{3}>0$.EKC curve is $\mathrm{N}$ form.

- $\beta_{1}<0, \beta_{2}>0, \beta_{3}<0$. EKC curve is inverted $\mathrm{N}$ form.

Turning points can be obtained at first derivative of three polynomial equal to zero.

\section{B. Changsha-Zhuzhou-Xiangtan Modeling Analysis}

In this paper, a case study in Changsha-ZhuzhouXiangtan, according to GDP per capita and ecological environmental quality indicator data from 1990 to 2010 in Changsha-Zhuzhou-Xiangtan (for a part of data are unable to accelerate, extract several sample data to explain the trend of 20 years), and by using the equation (2) to solve the result is as follows:

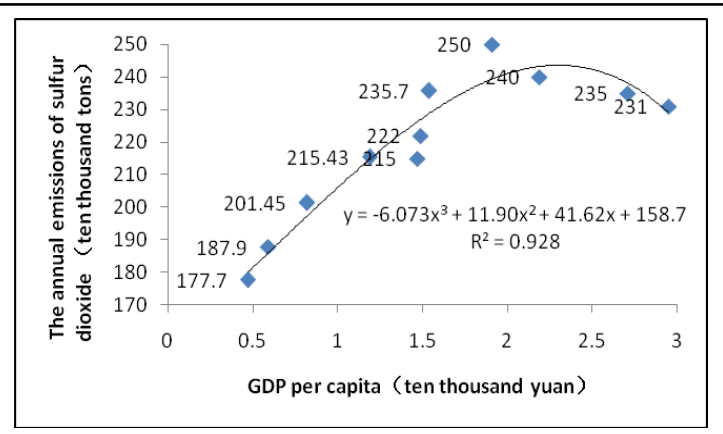

Figure 2. Curve between annual emissions of sulfur dioxide and GDP per capita in Changsha-Zhuzhou-Xiangtan

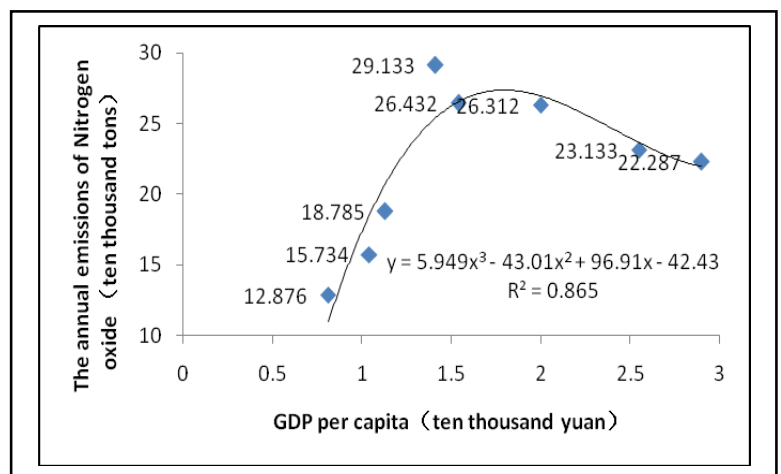

Figure 3. Curve between annual emissions of Nitrogen oxide and GDP per capita in Changsha-Zhuzhou-Xiangtan

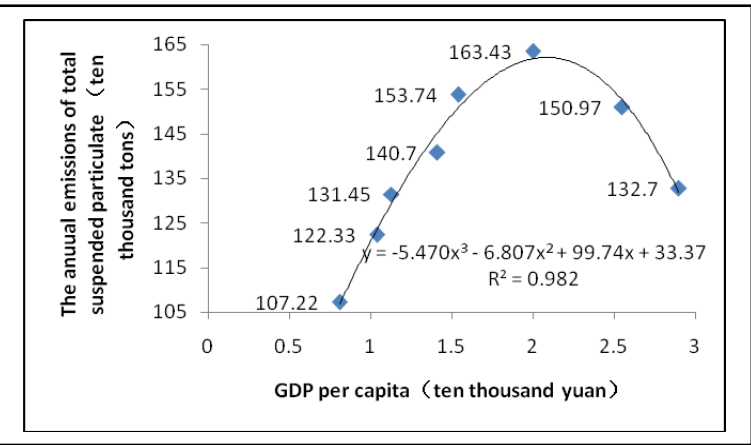

Figure 4. Curve between annual emissions of total suspended particulate and GDP per capita in Changsha-Zhuzhou-Xiangtan

Figure2 shows that the fitting curve between annual emissions of sulfur dioxide and GDP per capita in Changsha-Zhuzhou-Xiangtan is $\mathrm{y}=-6.073 \mathrm{x}^{3}+11.90 \mathrm{x}^{2}+$ $41.62 x+158.7, R^{2}=0.928$, the shape is the left (indicates increasing) of inverted $U$ shape curve and the beginning of right (indicates descending). Figure 3 shows that the fitting curve between annual emissions of Nitrogen oxide and GDP per capita in Changsha-Zhuzhou-Xiangtan is $\mathrm{y}=5.949 \mathrm{x}^{3}-$ $43.01 x^{2}+96.91 x-42.43, R^{2}=0.865$, its shape also present the left the inverted $U$ curve and a part of right, Figure4 shows that the fitting curve between annual emissions of total suspended particulate and GDP per capita in Changsha-Zhuzhou-Xiangtan is $\mathrm{y}=-5.470 \mathrm{x}^{3}-6.807 \mathrm{x}^{2}+$ $99.74 x+33.37, R^{2}=0.982$, the shape still appears same trend as above two curves.

According to three figures, it can be found that the turning point appeared on 2006(GDP per capita is 20 thousand yuan approximately). After 2006, ChangshaZhuzhou-Xiangtan' high-tech industry grow sturdily, environmental protection has been strengthened, the deterioration of environmental quality has been controlled well, the fitting curve appears a turning point.

\section{SUGGESTIONS}

Several policy suggestions are proposed to promote Changsha-Zhuzhou-Xiangtan' economic and ecological environmental development rapidly: 
a) Sustainable development should be considered firstly when speed up urbanization. Establish resource-saving and environment-friendly society. Keep sustainable development as the main line of economic development all the time.

b) Change the economic development mode, continue to promote industrial restructuring and upgrading, optimize industrial structure, and accelerate the hightech industry development.

c) Implement the environmental protection system's innovation, strengthen environmental supervision and enforce environmental protection law, establish the market-oriented environmental protection system, increase environmental protection investment.

\section{ACKNOWLEDGMENT}

The authors gratefully acknowledge the very helpful comments and suggestion given by Professor Zhao Pengda and two anonymous referees.

Humanity and Social Science Youth foundation of Ministry of Education(No. 12YJC790229)

\section{REFERENCES}

[1] Grossman G, Krueger A. Environmental impacts of the North American free trade agreement[C].Geneva: NBER, Working Paper, No.3914, 1991.

[2] Panayotou T. Empirical tests and policy analysis of environmental degradation at different stages of economic development[C].Geneva:
Working Paper WP238, Technology and Employment Programme, International Labour Office, 1993.

[3] Selden T.M, Song Daqin. Environmental quality and development: Is there a Kuznets curve for air pollution[J].Journal of Environmental Economics and Environmental Management. 1994, pp.147-162.

[4] X.D. Diao, S.X. Zeng, C.M. Tam, Vivian W.Y. Tam.EKC analysis for studying economic growth and environmental quality: a case study in China[J]. Journal of Cleaner Production. 2009, pp.541-548.

[5] Elif Akbostancı, Serap Turu t-As-1k, G. I pek Tunc.The relationship between income and environment inTurkey:Is there an environmental Kuznets curve? [J]. Energy Policy.2009, pp. 861-867.

[6] Md. Danesh Miah, Md.Farhad Hossain Masum , MasaoKoike .Global observation of EKC hypothesis for $\mathrm{CO}$, SOx and NOx emission: A policy understanding for climate change mitigation in Bangladesh[J]. Energy Policy.2010, pp. 4643-4651.

[7] Mohamed El Hedi Arouri, Adel BenYoussef, Hatem M'henni, Christophe Rault.Energy consumption,economic growth and $\mathrm{CO} 2$ emissions in Middle East and North African countries[J]. Energy Policy.2010, pp. 342-349.

[8] Muhammad Shahbaz, Hooi Hooi Lean, Muhammad Shahbaz Shabbir Environmental Kuznets Curve hypothesis in Pakistan: Cointegration and Granger causality[J]. Renewable and Sustainable Energy Reviews. 2012, pp.2947- 2953.

[9] George E. Halkos, Nickolaos G. Tzeremes.Economic growth and environmental efficiency: Evidence from US regions[J]. Economics Letters.2013,pp.48-52.

[10] Li Jian, Zhang Shanshan.Tianjin Eco-environmental Pressures and Economic Growth on the EKC Curve Analysis[C]. International Conference on Computing, Control and Industrial Engineering,2010.

[11] Zhang Xiao.The overall assessment of China's environmental policy[J]. Chinese Social Science.1999,pp.88-99. 